\title{
Assessing the Benefits of Remanufacturing Option under One-way Substitution and Capacity Constraint
}

\author{
Z. Pelin Bayındır ${ }^{1}$ \\ Econometric Institute \\ Erasmus University Rotterdam \\ Nesim Erkip, Refik Güllü \\ Department of Industrial Engineering \\ Middle East Technical University \\ June, 2003
}

Econometric Institute Report 2003-19

\begin{abstract}
In this article, we investigate the profitability of remanufacturing option when the manufactured and remanufactured products are segmented to different markets and the production capacity is finite. It is assumed that remanufactured products can be substituted by the manufactured ones. A single period profit model under substitution is constructed to investigate the system conditions under which remanufacturing is profitable. We present analytical findings and computational results to show profitability of remanufacturing option under substitution policy subject to a capacity constraint of the joint manufacturing/remanufactruing facility. Keywords: Remanufacturing; Inventory; One-way Substitution; Capacity Constraint
\end{abstract}

\footnotetext{
${ }^{1}$ Corresponding author. Econometric Institute, Erasmus University Rotterdam, POB 1738, 3000DR Rotterdam, The Netherlands, E-mail: bayindir@few.eur.nl
} 
Consider the supply chain of a tire manufacturer and its retail outlet. Both brand new and retreated tires are manufactured and sold to customers. There is a natural segmentation (primarily based on exogenously set unit selling prices) of market demand for tires, and customers for each segment (brand new and retreated) arrive in two independent streams. Concerned with losing potential customers, manufacturer's possible market strategy is to allow demand substitution among different tire classes. Specifically, customers for retreated tires are allowed to purchase a brand new tire, by paying the price of a retreated tire, if the retail store is out of retreated tire stock. Production and/or logistics stages utilized by brand new and retreated tires show some commonality (these may include production resources, storage and transportation space). Due to demand substitution strategy employed and use of common resources, stock replenishment decision of both classes of tires should be made in coordination. Therefore, the manufacturer has to determine the amounts of inventory to stock from brand new and retreated tires in the face of uncertain demand and common capacity constraint.

In this article we consider such a segmented market for manufactured and remanufactured products. Examples for such environments can be found in the studies reporting the real life applications of remanufacturing on reconditioned photocopiers, retreated tires and reconditioned (upgraded) computers. Ferrer [1] reports that reconditioned and new computers are segmented to completely different markets. Another example for segmented market is given by Ferrer [2]. He reports that, although the manufacturers give the same quality warranties for retreated tires as the new ones, they are sold at a lower price than the new ones. The same situation is reported by Ayres et al. [3] and Maslennikova and Foley [4] for reconditioned copiers. Maslennikova and Foley [4] report that reconditioned copiers are sold at a lower price level than the brand-new ones. Ayres et al. [3] report that for the case of reconditioned copiers, demand is higher than supply and the demand for reconditioned copiers is satisfied by the new ones when there is no reconditioned product available.

Inventory planning for the remanufacturers is investigated by several authors in the literature. Richter [5], Richter and Dobos [6], Richter and Sombrutzki [7], Teunter [8] are examples for the deterministic models where the main aim is to investigate the effect of returns on the optimal order quantity. Stochastic version of the problem is studied by van der Laan et al. [9], [10], [11], [12], van der Laan and Salomon [13], Toktay et al. [14], Bayındır et al. [15], 
Inderfurth et al. [16], Keismüller and van der Laan [17], Inderfurth and van der Laan [18]. In all these studies in the literature it is assumed that the customers are indifferent between buying manufactured or remanufactured products. In other words, the manufactured and remanufactured products are identical for the customers, and customer demand is generated from a single stream.

Debo et al. [19] consider strategic level, joint market segmentation and technology selection problem. It is assumed that the manufacturer is a monopolist so that he can determine the price level of both manufactured and remanufactured products, in addition he is able control the remanufacturability level by choosing the production technology. The objective is to find level of remanufacturibility and price levels of manufactured and remanufactured products maximizing average profit over infinite planning horizon. Their main focus is the investigation of profitability of remanufacturing as an option of satisfying demand of low-end customers who are willing to pay less and the operational issues are ignored in the study.

Inventory planning under demand substitution is studied by several authors in the literature. Parlar [20], [21], Pasternack and Drezner [22], Wang and Parlar [23], Bassok et al. [24], Smith and Agrawal [25] consider single period problem. The multi-period case of the problem is studied by Ignall and Veinott [26], McGillivray and Silver [27], Avsar and Baykal-Gürsoy [28] and Bayindır et. al. [29]. In most of the work done, two substitutible products are considered and game theory is utilized to determine the stock levels([22], [24], [28]). The model studied in [22] is the closest one to our study. The differences are discussed in Section 1. To the best of our knowledge the current study is the first attempt to include the capacity constraint under substitution policy in a single period setting.

The main aim of our study is to investigate the system conditions; under which utilization of remanufacturing option provides profit improvement. The system conditions investigated are different revenue/cost schemes, the capacity requirement of manufacturing and remanufacturing operations, and demand for manufactured and remanufactured products. There is a distinct demand for the remanufactured product. Our analysis is focused on the case where it is possible to substitute remanufactured products by brand new ones. While constructing the model, returns to be remanufactured are not explicitly considered. We assume that a sufficient return flow can be maintained incurring some cost that is included in the unit cost of remanufacturing. 
Therefore, the main objective of this study is to investigate the question "if the return availability can be maintained by the producer, to what extent remanufacturing option is utilized?". Due to not considering the return flow explicitly in the analysis, the model constructed can be used to analyze more general systems in addition to joint manufacturing/remanufacturing environment, where the assumptions on unit cost and revenue parameters and capacity scheme are valid.

Our work extends the existing research and makes five major contributions by:

i. investigating a model under a capacity constraint with two customer classes,

ii. deriving analytical conditions for profitability of remanufacturing,

iii. obtaining characterization for behavior of optimal solution with respect to system parameters,

iv. investigating risk reducing benefits of substitution policy,

v. computational analysis to investigate optimal utilization ratio of remanufacturing.

The outline of the paper is as follows: In Section 1 the problem definition is made. In Section 2 construction of the expected profit function is given for unconstrained and constrained versions of the problem. In Section 3 the results of the experimental study carried out are discussed. Finally, in Section 4 the managerial insights drawn from the analytical and numerical findings are discussed.

\section{Problem Definition}

We consider a situation where the manufactured $(\mathrm{PM})$ and remanufactured products $(\mathrm{PR})$ are non-identical, therefore the customers have a preference to buy one of them, and there are two distinct demand streams for two types. We consider the situation where the manufacturer is a price taker and has no control on market prices. The selling price of PM is assumed to be greater than or equal to the selling price of PR, like in most of the real life cases. At the given price levels of the products, demand for manufactured and remanufactured products are independent of each other. We assume that demand for each type is stochastic with known underlying distributions. Unsatisfied demand is lost. There is no penalty cost for lost sales, other than opportunity cost of earning profit margin. 
One-way substitution policy is employed by the manufacturer. When the PR inventory runs out of stock, PM product, if available, is sold to PR customers at the quoted price of PR. We assume that all PR customers accept the substitution. There is no cost associated with substitution. We allow unit cost of manufacturing and remanufacturing to be non-identical and do not make any assumptions on their relative values.

The main reason behind applying such a substitution policy without considering the unit costs of manufacturing and remanufacturing, is not to lose the remanufacturing customers' goodwill. There may be situations where the producer would employ such a policy, even though the unit profit earned by substituting remanufactured product may be very low, even negative, especially during early phases of remanufacturing application. In these cases, it is meaningful to keep the customers for remanufactured product satisfied and try to maintain their loyalty with the hope that remanufacturing technology will improve in the future and as a result unit costs will be lowered. Alternatively, there may be some restrictions taking place in legislation regarding environmental issues that may enforce such a policy.

In this study our main objective is to investigate the basic system conditions under which utilization of remanufacturing option provides profit improvement under substitution policy considered. The system conditions investigated are revenue and cost schemes and capacity requirements for remanufacturing and manufacturing options. While doing that, we do not explicitly consider (i) the availability of returns, and (ii) fixed costs of manufacturing and remanufacturing operations under which additional economies exist due to batching decisions. We think that sufficient return flow can be maintained incurring some cost that can be included in unit remanufacturing cost. Therefore, carrying out sensitivity with respect to unit cost of remanufacturing, we determine the desired level of remanufacturing giving the desired level of returns. Concerns on the feasibility, i.e. either economical viability or simply profitability, of remanufacturing can be questioned and analyzed by simple models, i.e. single period problem for strategic decisions, or by more detailed models, i.e. multi-period problem, for tactical level decisions. In that respect, determining a "feasible" set of unit remanufacturing costs becomes a very important factor before considering alternative actions for returns.

It is assumed that lead time of remanufacturing and manufacturing is less than a period. In other words we ignore the effect of lead times. There is no fixed cost associated with 
manufacturing or remanufacturing. Unit manufacturing and remanufacturing costs are allowed to be non-identical. The variable cost of remanufacturing includes the cost reverse logistics, i.e. necessary payments to the customers and costs associated for the collection of returns.

The capacity of the system is finite. Manufacturing and remanufacturing operations are performed utilizing the common system capacity. We do not consider the stages of manufacturing and remanufacturing. Instead, we assume that manufacturing (or remanufacturing) a product requires the utilization of certain amount of available capacity. Unit capacity requirement for manufacturing and remanufacturing are allowed to be non-identical.

The objective is to maximize expected profit when order-up-to levels for two types of products are decision variables. Given the features of the environment, the problem under single period planning horizon resembles to a newsboy environment with two products under one way stock-out based substitution. The solution of this model is a myopic solution to the multi-period case and can be implemented as a heuristic solution.

Capacity restriction imposes a linear constraint on order-up-to levels of manufactured and remanufactured products (under the assumption that initial inventory levels are zero for both types) on the problem.

The unconstrained model constructed is in the spirit of the one proposed by by Pasternack and Drezner [22]. The main differences between the model by Pasternack and Drezner [22] and our unconstrained model are, (i) in the former study the analysis depends on the joint demand density distribution, and (ii) revenue and cost items are different. In the model by Pasternack and Drezner [22], the selling prices, unit purchasing and shortage costs and unit salvage values of the products are included in the analysis. It is assumed that in case of substitution, a unit revenue different than the selling price is gained. We ignore the shortage cost and salvage value which are, in general, difficult to estimate and focus on basic unit revenue and cost parameters.

\section{Characterization of the Expected Profit Function and the Optimal Inventory Policy}

In the introduction of this section we introduce first the notation used throughout this article and expected profit function under substitution policy. In Section 2.1 we present the optimality 
conditions of the unconstrained problem (through joint concavity of the objective function) and a partial characterization of the optimal solution (Theorem 1). In Section 2.2 we derive optimality conditions for the constrained problem, and in Theorem 2 and Theorem 3 we present the behavior of the optimal solution with respect to system parameters. In Section 2.3 we investigate the implications of employing the substitution policy on the optimal order-up-to levels.

\section{$\underline{\text { Parameters }}$}

$p_{m}$ : unit selling price for PM,

$p_{r}$ : unit selling price for $\mathrm{PR}, p_{r} \leq p_{m}$,

$c_{m}$ : unit manufacturing cost,

$c_{r}$ : unit remanufacturing cost,

$X_{m}$ : random variable denoting demand/period for PM,

$X_{r}$ : random variable denoting demand/period for PR,

$f_{m}($.$) : probability density function for demand/period for PM,$

$f_{r}($.$) : probability density function for demand/period for PR,$

$\bar{F}_{m}($.$) : complementary cumulative distribution function for demand/period for PM,$

$\bar{F}_{r}($.$) : complementary cumulative distribution function for demand/period for PR,$

$\mathcal{L}_{i}($.$) : expected number of sales under f_{i}(),. i \in\{r, m\}$,

$$
\mathcal{L}_{i}(y)=\int_{0}^{y} x_{i} f_{i}\left(x_{i}\right) d x_{i}+\int_{y}^{\infty} y f_{i}\left(x_{i}\right) d x_{i}, y \geq 0, x_{i} \in\left\{x_{r}, x_{m}\right\}
$$

$C$ : available capacity in a period,

$a_{m}$ : capacity requirement for producing one unit of PM,

$a_{r}$ : capacity requirement for producing one unit of $\mathrm{PR}$,

Decision Variables

$S_{m}$ : order-up-to level for PM items,

$S_{r}$ : order-up-to level for PR items.

\subsection{Unconstrained Problem}

Since $p_{m} \geq p_{r}$, PM products are used to satisfy demand for PM with priority. In other words, the available stock for PM faces first its original demand and then, the remaining items are 
treated as PR. Hence expected profit becomes:

$$
\begin{aligned}
P\left(S_{r}, S_{m}\right)= & p_{m} \min \left\{S_{m}, x_{m}\right\}-c_{m} S_{m} \\
& +p_{r} \min \left\{S_{r}+\max \left\{S_{m}-x_{m}, 0\right\}, x_{r}\right\}-c_{r} S_{r} .
\end{aligned}
$$

Therefore expected profit is,

$$
\begin{aligned}
E\left[P\left(S_{r}, S_{m}\right)\right]= & p_{m} \mathcal{L}_{m}\left(S_{m}\right)-c_{m} S_{m} \\
& +p_{r} \int_{0}^{S_{m}} \mathcal{L}_{r}\left(S_{r}+S_{m}-x_{m}\right) f_{m}\left(x_{m}\right) d x_{m} \\
& +p_{r} \int_{S_{m}}^{\infty} \mathcal{L}_{r}\left(S_{r}\right) f_{m}\left(x_{m}\right) d x_{m}-c_{r} S_{r} .
\end{aligned}
$$

In the expected profit expression given in (1) it can be observed that expected number of PR sales depends on the PM demand realization, $x_{m}$. If the realized demand for PM is less than corresponding order-up-to level, i.e. $x_{m}<S_{m}$, expected PR sales can be expressed as if the order-up-to level for PR is $S_{r}+S_{m}-x_{m}$. Otherwise, expected PR sales are in regular form.

\subsubsection{The Behavior of the Expected Profit Function}

The first order optimality conditions with respect to decision variables $S_{r}$ and $S_{m}$ are,

$$
\begin{gathered}
\frac{\partial E\left[P\left(S_{r}, S_{m}\right)\right]}{\partial S_{m}}=p_{m} \bar{F}_{m}\left(S_{m}\right)-c_{m}+p_{r} \int_{0}^{S_{m}} \bar{F}_{r}\left(S_{r}+S_{m}-x_{m}\right) f_{m}\left(x_{m}\right) d x_{m} \\
\frac{\partial E\left[P\left(S_{r}, S_{m}\right)\right]}{\partial S_{r}}=p_{r}\left[\int_{0}^{S_{m}} \bar{F}_{r}\left(S_{r}+S_{m}-x_{m}\right) f_{m}\left(x_{m}\right) d x_{m}+\bar{F}_{r}\left(S_{r}\right) \bar{F}_{m}\left(S_{m}\right)\right]-c_{r} .
\end{gathered}
$$

$E\left[P\left(S_{r}, S_{m}\right)\right]$ is jointly concave in $\left(S_{r}, S_{m}\right)$ as it is shown in Appendix I. Therefore, $\left(S_{r}, S_{m}\right)$ pair maximizing $E\left[P\left(S_{r}, S_{m}\right)\right]$ can be found by equating equations (2) and (3) to zero.

The optimality conditions enable us to characterize some of the system conditions under which utilization of remanufacturing option is not profitable. The following theorem characterizes such a condition. 
Theorem 1 When the capacity is not limited $(C=\infty)$, it is not profitable to utilize remanufacturing option, that is, the optimal $S_{r}$ value, $S_{r}^{*}$, is zero, if unit cost of remanufacturing is greater than unit cost of manufacturing $\left(c_{r}>c_{m}\right)$.

Proof : See Appendix II.

\subsection{Effect of Finite Production Capacity}

The following problem should be solved to find optimal order-up-to level for PM and PR maximizing expected profit function subject to capacity constraint.

$$
\begin{aligned}
\operatorname{Max} E\left[P\left(S_{r}, S_{m}\right)\right] \quad & =p_{m} \mathcal{L}_{m}\left(S_{m}\right)-c_{m} S_{m} \\
& +p_{r} \int_{0}^{S_{m}} \mathcal{L}_{r}\left(S_{r}+S_{m}-x_{m}\right) f_{m}\left(x_{m}\right) d x_{m} \\
& +p_{r} \int_{S_{m}}^{\infty} \mathcal{L}_{r}\left(S_{r}\right) f_{m}\left(x_{m}\right) d x_{m}-c_{r} S_{r} \\
\text { s.t. } & a_{m} S_{m}+a_{r} S_{r} \leq C
\end{aligned}
$$

For the problem instances where the solution of the unconstrained problem violates the capacity constraint, Lagrangian approach should be utilized. Lagrangian relaxation gives the following Lagrangian function and optimality conditions:

$$
\begin{gathered}
\Lambda\left(S_{r}, S_{m}, \theta\right)=E\left[P\left(S_{r}, S_{m}\right)\right]+\theta\left(C-a_{m} S_{m}-a_{r} S_{r}\right) \\
\frac{\partial \Lambda\left(S_{r}, S_{m}, \theta\right)}{\partial S_{m}}=\frac{\partial E\left[P\left(S_{r}, S_{m}\right)\right]}{\partial S_{m}}-\theta a_{m}=0 \\
\frac{\partial \Lambda\left(S_{r}, S_{m}, \theta\right)}{\partial S_{r}}=\frac{\partial E\left[P\left(S_{r}, S_{m}\right)\right]}{\partial S_{r}}-\theta a_{r}=0 \\
\frac{\partial \Lambda\left(S_{r}, S_{m}, \theta\right)}{\partial \theta}=C-a_{m} S_{m}-a_{r} S_{r}=0
\end{gathered}
$$

where $\frac{\partial E\left[P\left(S_{r}, S_{m}\right)\right]}{\partial S_{m}}$, and $\frac{\partial E\left[P\left(S_{r}, S_{m}\right)\right]}{\partial S_{r}}$ are defined in (2) and (3), respectively, and $\theta \geq 0$ is the Lagrange multiplier and can be interpreted as the expected profit of utilizing one extra unit 
of capacity at the given capacity level, $C$, or alternatively as the expected cost of utilizing one less unit capacity at the given capacity level $C$. hence we name $\theta$ as the opportunity cost of utilizing a unit of capacity.

Since the imposed constraint is a linear function of both $S_{r}$ and $S_{m}$, the concavity results drawn for $E\left[P\left(S_{r}, S_{m}\right)\right]$ are also valid for the Lagrangian function $\Lambda\left(S_{r}, S_{m}, \theta\right)$. Therefore, $\left(S_{r}, S_{m}, \theta\right)$ tuple satisfying (5), (6) and (7) maximizes $\Lambda\left(S_{r}, S_{m}, \theta\right)$ and gives the optimal solution to the problem.

Using the concavity property of $\Lambda\left(S_{r}, S_{m}, \theta\right)$ and optimality conditions, it is possible to figure out the effect of capacity constraint on the optimal order-up-to level of PR. Theorem 2 summarizes the effect when the remanufacturing option is inferior to manufacturing with respect to unit costs, whereas in Theorem 3 the opposite case is considered.

Theorem 2 When the capacity is limited $(C<\infty)$ and remanufacturing option is inferior to manufacturing with respect to unit cost $\left(c_{r}>c_{m}\right)$,

(a.) if remanufacturing option is also inferior with respect to unit capacity requirement $\left(a_{r}>\right.$ $\left.a_{m}\right)$, the optimal $S_{r}$ value, $S_{r}^{*}$, is always zero, i.e. it is not profitable to utilize remanufacturing option under all available capacity levels, $C$,

(b.) if remanufacturing option has unit capacity requirement advantage $\left(a_{r}<a_{m}\right)$,

(i.) under available capacity levels, $C$, for which opportunity cost of utilizing a unit of capacity, $\theta$, is less than $\theta_{0}=\frac{c_{r}-c_{m}}{a_{m}-a_{r}}$, the optimal $S_{r}$ value, $S_{r}^{*}$, is always zero, i.e. it is not profitable to utilize remanufacturing option,

(ii.) under tighter available capacity levels, $C$, for which $\theta>\theta_{0}$, as the capacity gets tighter (as $\theta$ increases), the optimal $S_{r}$ value, $S_{r}^{*}$, shows a non decreasing behavior.

\section{Proof : See Appendix II.}

Theorem 3 When the capacity is limited $(C<\infty)$ and remanufacturing option has unit cost advantage over manufacturing $\left(c_{r}<c_{m}\right)$,

(a.) if remanufacturing option is inferior to manufacturing with respect to unit capacity requirement $\left(a_{r}>a_{m}\right)$, 
(i.) as the available capacity levels, $C$, gets tighter (as $\theta$ increases), the optimal $S_{r}$ value, $S_{r}^{*}$, shows a non increasing behavior.

(ii.) under available capacity levels, $C$, for which $\theta>\theta_{0}=\frac{c_{r}-c_{m}}{a_{m}-a_{r}}, S_{r}^{*}$, is always zero, i.e. it is not profitable to utilize remanufacturing option.

(b.) if remanufacturing option has also unit capacity requirement advantage $\left(a_{r}<a_{m}\right)$, the optimal $S_{r}$ value, $S_{r}^{*}$, shows a non decreasing behavior.

\section{Proof : See Appendix II.}

Table 1 summarizes the effect of increase in opportunity cost of utilizing a unit of capacity which is equivalent to a decrease in available capacity levels on the optimal $S_{r}$ depending on the conditions on unit cost and unit capacity requirements that are given in Theorem 2 , and 3.

\section{Place Table 1 here}

Theorem 2 shows that, if the remanufacturing option is inferior to manufacturing with respect to both unit cost and capacity requirement, it is never utilized in the optimal solution under the substitution scheme considered. From the same theorem, it can be observed that for the cases where manufacturing has unit cost and remanufacturing has the capacity requirement advantages, as the available capacity gets tighter, remanufacturing option is utilized since the unit cost of utilizing one unit of capacity will increase. In order for remanufacturing to be profitable, that is in order for $S_{r}^{*}>0$, when it is inferior to manufacturing with respect to unit cost, its capacity requirement should be lower than the capacity requirement of manufacturing and the opportunity cost of utilizing one unit of capacity, $\theta$, should be large enough. $\theta$ or equivalently $C$ value, under which remanufacturing starts to be utilized depends on cost and capacity requirement of both modes of production. Given the parameters of manufacturing option, as the unit cost and unit capacity requirement of remanufacturing decreases remanufacturing is utilized under a wider range of available capacity levels.

Theorem 3 states that when the remanufacturing channel has both unit cost and capacity requirement advantages, its order-up-to level is non decreasing while the capacity gets tighter. In this case, it is always profitable to utilize the remanufacturing option. On the other hand, 
when the remanufacturing option is inferior with respect to unit capacity requirement, order-upto level for PR decreases as the capacity gets tighter and remanufacturing channel is not utilized starting with a certain capacity level, even if it has a unit cost advantage. It can be observed that, the range of capacity levels under which remanufacturing is utilized increases as, the difference between both unit costs and capacity requirements of two options increases. In other words, as in the previous case, as the unit cost and capacity requirement of remanufacturing decreases it is utilized under a wider range of capacity levels.

\subsection{Effect of Substitution Policy on the Optimal Order-up-to Levels}

In this section, several properties describing the effect of substitution policy on the optimal order-up-to levels of two products are discussed.

When substitution policy is not applied, i.e. two inventory systems operate independently, expected profit function can be expressed as follows:

$$
E_{N S}\left[P\left(S_{r}, S_{m}\right)\right]=p_{m} \mathcal{L}_{m}\left(S_{m}\right)-c_{m} S_{m}+p_{r} \mathcal{L}_{r}\left(S_{r}\right)-c_{r} S_{r}
$$

It can be easily shown that the function $E_{N S}\left[P\left(S_{r}, S_{m}\right)\right]$ is jointly concave in $\left(S_{r}, S_{m}\right)$ and the optimal order-up-to levels, $S_{r}^{N S}$ and $S_{m}^{N S}$ can be found using the following equations:

$$
\begin{gathered}
\bar{F}_{r}\left(S_{r}^{N S}\right)=\frac{c_{r}}{p_{r}} \\
\bar{F}_{m}\left(S_{m}^{N S}\right)=\frac{c_{m}}{p_{m}}
\end{gathered}
$$

On the other hand, when there is an active capacity constraint, Lagrangian relaxation yields the following optimality conditions:

$$
\begin{gathered}
\bar{F}_{r}\left(S_{r}^{N S}\right)=\frac{c_{r}+\theta}{p_{r}} \\
\bar{F}_{m}\left(S_{m}^{N S}\right)=\frac{c_{m}+\theta}{p_{m}} \\
S_{m}^{N S}+S_{r}^{N S}=C
\end{gathered}
$$


Note that in this case the effect of capacity restriction on the optimal order-up-to levels is obvious: While the capacity gets tighter both $S_{r}^{N S}$ and $S_{m}^{N S}$ decreases since complementary cumulative distribution function is non increasing and due to (10), (11) and (12).

Using the optimality conditions under this case and substitution policy, the following properties can be shown.

Property 1: When there is no capacity restriction, the optimal order-up-to level for PM, $S_{m}^{*}$ obtained under substitution policy, is greater than or equal to the optimal order-up-to level for PM, $S_{m}^{N S}$, obtained under non-substitution policy.

Proof: See Appendix III.

Property 2: When there is no capacity restriction, the optimal order-up-to level for PR, $S_{r}^{*}$ obtained under substitution policy, is less than or equal to the optimal order-up-to level for $\mathrm{PR}, S_{r}^{N S}$, obtained under non-substitution policy.

Proof: See Appendix III.

Property 3: When there is an active capacity constraint, the optimal order-up-to level for $\mathrm{PM}, S_{m}^{*}$ obtained under substitution policy, is greater than or equal to the optimal order-up-to level for PM, $S_{m}^{N S}$, obtained under non-substitution policy, at the same opportunity cost of utilizing a unit of capacity, i.e. at the same $\theta$ level.

Proof: See Appendix III.

Property 4: When there is an active capacity constraint, the optimal order-up-to level for $\mathrm{PR}, S_{r}^{*}$ obtained under substitution policy, is greater than or equal to the optimal order-up-to level for PR, $S_{r}^{N S}$, obtained under non-substitution policy, at the same opportunity cost of utilizing a unit of capacity, i.e. at the same $\theta$ level.

Proof: See Appendix III.

Properties 1 and 2 show that for unconstrained problem under substitution the order-up-to level for PM increases, whereas it decreases for PR with respect to the no-substitution problem. On the other hand, when the capacitated problem is considered, these properties are valid at the same opportunity cost of utilizing a unit capacity $(\theta)$. However, note that we do not know whether the implied capacity levels corresponding to a certain $\theta$ level for substitution and nosubstitution problems are the same or not. Similarly, the effect of substitution policy on the sum of order-up-to levels is not clear. 
These properties are the results of risk-reducing benefits of substitution. Under substitution policy, manufacturing channel can be utilized to satisfy both types of demands. Therefore, the order-up-to level of manufactured products is higher with respect to no-substitution case to prevent the leftovers for PR. Pasternack and Drezner [22] report Property 1 and 2, both for the unconstrained problem .

Note that the value of optimal order-up-to level of PR and the behavior of the order-up-to level under substitution policy and capacity restriction give a little idea about the profitability of remanufacturing option. This is basically due to the fact that the order-up-to level heavily depends on the demand size. Therefore, it is hard to comment on the optimal utilization of remanufacturing option just concentrating on the the order-up-to level of remanufactured products. In order to derive general managerial insights on the profitability of remanufacturing option, we consider the utilization ratio of remanufacturing option, $r=\frac{S_{r}}{S_{r}+S_{m}}$, as a measure. Note that since we do not have any analytical observations on the effect of substitution policy or capacity restriction on the optimal system-wide order-up-to level, $S_{r}+S_{m}$, we carried out a numerical study. In Section 3, the profitability of remanufacturing option is investigated for a set of problems under substitution, as well as under no-substitution using utilization ratio of remanufacturing option as an indicator of profitability of remanufacturing.

\section{$3 \quad$ Numerical Study}

The main aim of the computational study is to investigate the optimal utilization ratio of remanufacturing option and effect of substitution policy on profitability of remanufacturing option under different unit revenue/cost parameters and unit capacity requirements at different capacity levels.

We study a number of scenarios. In all scenarios unit price of PR and PM, $p_{r}$ and $p_{m}$, is set to 1.5 and 2, respectively. The profit margin of PM is kept unvaried by setting unit manufacturing cost to 0.75 . The following three cases are considered for the unit remanufacturing cost.

Case A: Unit profit margin is significantly higher for the remanufactured product, $c_{r}=$ $0.1\left(<c_{m}\right)$,

Case B: Unit profit margin is slightly higher for the manufactured product, $c_{r}=0.375(<$ 
$\left.c_{m}\right)$

Case C: Unit profit margin is significantly higher for the manufactured product, $c_{r}=$ $0.8\left(>c_{m}\right)$.

Similarly, unit resource requirement of manufacturing, $a_{m}$, is set to 1 , while for the parameter $a_{r}$, three different levels, $0.5,1$ and 2 are considered.

Under each case, 6 different demand scenarios are considered;

S1. $x_{r}, x_{m} \sim$ Poisson, $E\left[x_{r}\right]=E\left[x_{m}\right]=4$,

S2. $x_{r}, x_{m} \sim$ Poisson, $E\left[x_{r}\right]=4, E\left[x_{m}\right]=2$,

S3. $x_{r}, x_{m} \sim$ Poisson, $E\left[x_{r}\right]=2, E\left[x_{m}\right]=4$,

S4. $x_{r}, x_{m} \sim$ Exponential, $E\left[x_{r}\right]=E\left[x_{m}\right]=4$,

S5. $x_{r}, x_{m} \sim$ Exponential, $E\left[x_{r}\right]=4, E\left[x_{m}\right]=2$,

S6. $x_{r}, x_{m} \sim$ Exponential, $E\left[x_{r}\right]=2, E\left[x_{m}\right]=4$,

Under each demand scenario, all three cases are considered with three different $a_{r}$ levels. Different available capacity levels are considered by varying Lagrange multiplier, $\theta$, for $\theta \in$ $\left[0, \theta_{u}\right]$, where $\theta_{u}=\max \left\{\frac{p_{m}-c_{m}}{a_{m}}, \frac{p_{r}-c_{r}}{a_{r}}\right\}$. Notice that under $\theta_{u}$ either of the products' profit margin (including opportunity cost of utilizing a unit of capacity) drops to zero under the available capacity.

For each problem instance, the optimal $\left(S_{r}, S_{m}\right)$ pair is found under substitution policy and for the case where the substitution policy is not applied, as well. We consider the utilization ratio of remanufacturing option, $r=\frac{S_{r}}{S_{r}+S_{m}}$, as a measure. $r_{S}$ and $r_{N S}$ are referred for the utilization ratio of remanufacturing under one-way substitution and independent operation of two systems, respectively.

For the problems settings in S4, S5, S6, the derived optimality conditions are used to find optimal $\left(S_{r}, S_{m}\right)$ pair. On the other hand, when the demand parameters are Poisson random variables, we could neither prove that the objective function is jointly concave in decision variables nor found counter examples. Therefore, a full search procedure that evaluates 
the expected profit function at each step is utilized. Nevertheless, aside from the difficulties associated with discrete functions, we expect that the expected profit function to be discrete concave under Poisson demands.

The raw results are available upon request. Investigating the results obtained yields the following observations:

Observation 1. $r_{S}$ is always less than $r_{N S}$ at the same $\theta$ level.

A typical case is depicted in Figure 1. Although we do not observe any consistent effect of substitution on system-wide order-up-to level, $S_{r}+S_{m}$, under all of the problem settings considered the effect of substitution policy on the utilization ratio of remanufacturing option is the same as the effect on the optimal $S_{r}$ as it is shown analytically in Section 2.3. Note that the observation on $S_{r}+S_{m}$ is also reported by Pasternack and Drezner $[22]$.

$$
\text { Place Figure } 1 \text { here }
$$

Observation 2. When the capacity requirement is higher for $\mathrm{PR}\left(a_{r}>a_{m}\right)$, both $r_{S}$ and $r_{N S}$ decreases, as the available capacity gets tighter.

A typical case is given in Figure 2 and in Figure 3 for the substitution and no-substitution policies, respectively. Note that, under substitution for Case $\mathrm{C}$ where $c_{r}>c_{m}$, the remanufacturing is not utilized at all available capacity levels due to Theorem 2 when $a_{r}>a_{m}$. As it can be seen in Figure 2 and in Figure 3 the effect of the capacity constraint on $r$ is the same as on the optimal $S_{r}$ value shown analytically in Theorem 3 .

\section{Place Figure 2 and Figure 3 here}

From these figures it can be observed that, as the capacity gets tighter, the optimal utilization ratio of remanufacturing decreases and hits zero at a certain capacity level, call it $C^{0}$, even if the PR product has unit profit margin and / or unit cost advantages. At capacity levels tighter than $C^{0}$ remanufacturing is not utilized in the optimal solution, i.e. the pure strategy where only manufacturing is utilized is optimal. In Table 2 and Table 
$3, C^{0}$ values are reported under substitution and no-substitution, respectively. Note that the results in Table 2 under the Column Case C have already been described by Theorem 2. The following observations are made on these tables;

\section{Place Table 2 and Table 3 here}

Observation 2.1. When the capacity requirement is higher for $\mathrm{PR}$, as the unit cost of PR increases (and consequently unit profit margin of PR decreases), the range of capacity levels under which remanufacturing is not utilized increases under both substitution and no-substitution.

As the unit cost of PR increases, the desired service-level for PR decreases under both substitution and no-substitution. When the system has finite capacity, the utilization ratio of remanufacturing hits zero at a greater capacity level. Therefore, $C^{0}$ values increase from Case A to Case $\mathrm{C}$. This observation is consistent with our analytical findings on optimal $S_{r}$ and $\theta$ values under which $S_{r}$ drops to zero given in Theorem 3.

Observation 2.2. When the capacity requirement for PR is higher, remanufacturing is utilized under a wider range of capacity levels when the substitution policy is not applied.

Due to the fact that applying substitution gives an opportunity of satisfying demand for PR by PM which require less resources, $C^{0}$ values are higher under substitution. When substitution policy is applied, it is better to allocate whole capacity to PM products at fairly tighter capacity levels, since they can be utilized to satisfy both PR and PM demand. On the other hand, when two inventory systems operate independently, some capacity is allocated to PR product which has a positive profit margin at the same capacity level. Even if the unit profit margin earned by substitution is lower than regular profit margin of PR (Case A and Case B), this behavior which shows the risk-pooling opportunity of substitution policy, is observed.

Observation 3. When the capacity requirement is lower for $\mathrm{PR}\left(a_{r}<a_{m}\right)$, optimal utilization ratio of remanufacturing increases, as the available capacity gets tighter under both substitution and no-substitution policies. 
A typical case is given in Figure 4 and in Figure 5 for the substitution and no-substitution policies, respectively.

\section{Place Figure 4 and Figure 5 here}

From these figures it can be observed that, as the capacity gets tighter, the optimal utilization ratio of remanufacturing increases (like the optimal $S_{r}$ which is shown in Theorem 3 ) and reaches to one at some capacity level, call it $C^{1}$, even if the PM product has unit profit margin and / or unit cost advantages. At capacity levels tighter than $C^{1}$ manufacturing is not utilized in the optimal solution, i.e. under the capacity levels lower than $C^{1}$, the pure strategy where only remanufacturing is utilized is optimal. In Table 4 and Table $5, C^{1}$ values are reported under substitution and no-substitution, respectively. The following observations are made on these tables;

\section{Place Table 4 and Table 5 here}

Observation 3.1. When the capacity requirement is lower for PR, under both substitution and no-substitution policies as the unit cost of PR decreases (and consequently unit profit margin of PR increases), the range of capacity levels under which whole capacity is allocated to remanufacturing (and therefore) only remanufacturing is utilized increases.

As the unit cost of PR decreases, the desired service level for PR increases. In addition when the substitution policy is applied, unit profit margin loss due to substitution increases, when the unit cost of PR is lower. Therefore, the pure strategy with remanufacturing is utilized for a wider range of capacity levels.

We expect to observe that the range of capacity levels where only remanufacturing is utilized is narrower under substitution, at least for Case $\mathrm{C}$ where $\mathrm{PR}$ is inferior with respect to both unit cost and unit profit margin. However, no consistent effect of substitution policy on $C^{1}$ values is observed.

Observation 4. Profit improvement by substitution mostly depends on the available capacity level and relative resource requirements of PM and PR. As the opportunity cost of 
utilizing a unit of capacity increases and the unit capacity requirement of remanufacturing increases, the percent profit improvement by substitution policy over the case where two systems operate independently increases.

It is observed that the substitution policy improves the expected profit figures even if the unit cost of PM is higher than unit cost of PR, if the opportunity cost of utilizing one unit of capacity is sufficiently high. In Figure 6, a typical case is depicted. Notice that the figure is for Case A where remanufacturing has the highest unit cost advantage. In other cases, percent improvement figures are higher than this case and it is substantial when the capacity is even tighter.

$$
\text { Place Figure } 6 \text { here }
$$

One-way substitution is most beneficial for the systems where

- remanufacturing requires more capacity than manufacturing,

- capacity of the system is very tight,

- unit cost of PR is higher than the unit cost of PM.

Although we do not have any sensitivity results with respect to relative prices of PM and $\mathrm{PR}$, it is obvious that substitution is more profitable when unit prices are close to each other.

\section{Conclusion}

In this study, we consider a segmented market for manufactured and remanufactured products. Mainly we focused on the case, where it is possible to substitute remanufactured products by manufactured one. The computational analysis is restricted to the single period problem to investigate the effect of substitution on optimal utilization of remanufacturing option under capacity constraint.

The analytical results and the observations on the computational study result in the following managerial insights; 
- When remanufacturing is inferior in unit cost and capacity requirement with respect to manufacturing, it is optimal to satisfy whole demand by manufactured ones if substitution is possible. In these cases, substitution improves the expected profits.

- When remanufacturing is inferior in unit cost, but requires less capacity than manufacturing, at tight capacity levels it is utilized even if substitution is possible. As the difference between unit costs decreases and/or the unit capacity requirement of remanufacturing decreases, remanufacturing becomes a plausible option under a wider range of available capacity levels.

- When remanufacturing is inferior in unit capacity requirement, even if it has a unit cost advantage it is not profitable under tight capacity levels.

- When the cost of utilizing a capacity is high, application of the substitution policy improves the profit figures even if remanufacturing is superior to manufacturing in unit cost, unit profit margin and capacity requirement.

- Optimal utilization of remanufacturing mostly depends on the capacity requirement and available capacity of the system under both substitution and no-substitution. It is optimal to utilize only the channel with lower capacity requirement when the available capacity is low. The range of capacity levels under which remanufacturing is not utilized is lower under substitution.

The current work can be extended to multi-period environment for more tactical and operational level decisions using dynamic programming (DP) formulation. In this way it is possible to capture the effects of having non-identical lead-times of the options, inventory carrying and fluctuating capacity over the periods. The substitution decision may be included in the model by considering the amount of PR demand substituted in each period. However, note that all these additional properties will result in a relatively difficult problem for solution, even if one can come up with a DP formulation.

\section{Appendix I-Concavity of Expected Profit Function under Substitution Policy}

The second order optimality conditions can be expressed as, 


$$
\begin{aligned}
\frac{\partial^{2} E\left[P\left(S_{r}, S_{m}\right)\right]}{\partial S_{m}^{2}} & =-f_{m}\left(S_{m}\right)\left[p_{m}-p_{r} \bar{F}_{r}\left(S_{r}\right)\right] \\
& -p_{r} \int_{0}^{S_{m}} f_{r}\left(S_{r}+S_{m}-x_{m}\right) f_{m}\left(x_{m}\right) d x_{m} \leq 0
\end{aligned}
$$

since $p_{m}>p_{r}, \bar{F}_{r}\left(S_{r}\right) \leq 1, f_{r}(),. f_{m}() \geq$.0 . Therefore, $E\left[P\left(S_{r}, S_{m}\right)\right]$ is concave in $S_{m} \geq 0$ for a given $S_{r} \geq 0$ value.

$$
\frac{\partial^{2} E\left[P\left(S_{r}, S_{m}\right)\right]}{\partial S_{r}^{2}}=-p_{r}\left[\int_{0}^{S_{m}} f_{r}\left(S_{r}+S_{m}-x_{m}\right) f_{m}\left(x_{m}\right) d x_{m}+\bar{F}_{m}\left(S_{m}\right) f_{r}\left(S_{r}\right)\right] \leq 0
$$

since $\bar{F}_{m}() \geq 0,. f_{r}(),. f_{m}() \geq$.0 . Therefore, $E\left[P\left(S_{r}, S_{m}\right)\right]$ is concave in $S_{r} \geq 0$ for a given $S_{m} \geq 0$ value.

$$
\frac{\partial^{2} E\left[P\left(S_{r}, S_{m}\right)\right]}{\partial S_{m} S_{r}}=-p_{r} \int_{0}^{S_{m}} f_{r}\left(S_{r}+S_{m}-x_{m}\right) f_{m}\left(x_{m}\right) d x_{m}
$$

Determinant of the Hessian matrix can be expressed as,

$$
\begin{aligned}
|H|= & \frac{\partial^{2} E\left[P\left(S_{r}, S_{m}\right)\right]}{\partial S_{m}^{2}} \cdot \frac{\partial^{2} E\left[P\left(S_{r}, S_{m}\right)\right]}{\partial S_{r}^{2}}-\left(\frac{\partial^{2} E\left[P\left(S_{r}, S_{m}\right)\right]}{\partial S_{m} S_{r}}\right)^{2} \\
= & p_{r}^{2}\left[f_{m}\left(S_{m}\right)\left(\frac{p_{m}}{p_{r}}-\bar{F}_{r}\left(S_{r}\right)\right)\right] \int_{0}^{S_{m}} f_{r}\left(S_{r}+S_{m}-x_{m}\right) f_{m}\left(x_{m}\right) d x_{m} \\
& +p_{r}^{2} \bar{F}_{r}\left(S_{m}\right) f_{r}\left[f_{m}\left(S_{m}\right)\left(\frac{p_{m}}{p_{r}}-\bar{F}_{r}\left(S_{r}\right)\right)\right. \\
& \left.+\int_{0}^{S_{m}} f_{r}\left(S_{r}+S_{m}-x_{m}\right) f_{m}\left(x_{m}\right) d x_{m}\right] \geq 0
\end{aligned}
$$

since, $0 \leq \bar{F}_{r}() \leq 1,. p_{m} \geq p_{r}, f_{r}(),. f_{m} \geq 0$.

$E\left[P\left(S_{r}, S_{m}\right)\right]$ is jointly concave in $\left(S_{r}, S_{m}\right)$ due to (13), (14) and (15).

\section{Appendix II-Proof of Theorems}

Proof of Theorem 1: Let $S_{m}^{*}\left(S_{r}\right)$ be the optimal order-up-to level for PM, for given value of $S_{r}$. Under $S_{m}^{*}\left(S_{r}\right), \frac{\partial E\left[P\left(S_{r}, S_{m}\right)\right]}{\partial S_{m}}=0$. Therefore from (2), 


$$
\int_{0}^{S_{m}} \bar{F}_{r}\left(S_{r}+S_{m}-x_{m}\right) f_{m}\left(x_{m}\right) d x_{m}=\frac{c_{m}-p_{m} \bar{F}_{m}\left(S_{m}\right)}{p_{r}} .
$$

Plugging (16) into (3) yields,

$$
\frac{\partial E\left[P\left(S_{r}, S_{m}^{*}\left(S_{r}\right)\right)\right]}{\partial S_{r}}=\bar{F}_{m}\left(S_{m}\right)\left(p_{r} \bar{F}_{r}\left(S_{r}\right)-p_{m}\right)+c_{m}-c_{r}<0 \forall S_{r},
$$

since $\bar{F}_{m}() \geq 0,. \bar{F}_{r}() \leq 1,. p_{r} \leq p_{m}, c_{m}<c_{r}$. Therefore, $E\left[P\left(S_{r}, S_{m}^{*}\left(S_{r}\right)\right)\right]$ is a non increasing function of $S_{r}$. Therefore, the optimal $S_{r}=0$, when $c_{r}>c_{m}$.

The following Lemma 1 and 2 are used to prove Theorem 2 and 3.

Lemma 1 For the problem instances where the solution of the unconstrained problem violates capacity constraint, when $S_{m}$ is set such that it is optimal for a given value of $S_{r} \geq 0$, the derivative of the Lagrangian

function that is given in (4) with respect to $S_{r}$ can be expressed as follows:

$$
\frac{\partial \Lambda\left(S_{r}, S_{m}^{*}\left(S_{r}\right), \theta\right)}{\partial S_{r}}=\bar{F}_{m}\left(S_{m}\right)\left(p_{r} \bar{F}_{r}\left(S_{r}\right)-p_{m}\right)+c_{m}-c_{r}+\theta\left(a_{m}-a_{r}\right)
$$

where $S_{m}^{*}\left(S_{r}\right)$ is the optimal $S_{m}$, for given value of $S_{r}$.

Proof: When the capacity constraint is binding, under $S_{m}^{*}\left(S_{r}\right)$, the optimality condition given in (5) holds. Therefore from (5),

$$
\int_{0}^{S_{m}} \bar{F}_{r}\left(S_{r}+S_{m}-x_{m}\right) f_{m}\left(x_{m}\right) d x_{m}=\frac{c_{m}+\theta a_{m}-p_{m} \bar{F}_{m}\left(S_{m}\right)}{p_{r}} .
$$

Plugging (18) into $\frac{\partial \Lambda\left(S_{r}, S_{m}, \theta\right)}{\partial S_{r}}$ expression given in (6) yields (17).

Lemma 2 For a given value of $\theta>0$,

(i.) if $c_{m}-c_{r}+\theta\left(a_{m}-a_{r}\right)<0, \frac{\partial \Lambda\left(S_{r}, S_{m}^{*}\left(S_{r}\right), \theta\right)}{\partial S_{r}}<0$ for $\forall S_{r} \geq 0$, and the optimal $S_{r}, S_{r}^{*}=0$.

(ii.) otherwise $\frac{\partial \Lambda\left(S_{r}, S_{m}^{*}\left(S_{r}\right), \theta\right)}{\partial S_{r}}$ decreases from positive to negative as $S_{r}$ increases and under $S_{r}^{*}$ $\frac{\partial \Lambda\left(S_{r}, S_{m}^{*}\left(S_{r}\right), \theta\right)}{\partial S_{r}}$ given in (17) is zero.

\section{Proof:}


(i.) When $c_{m}-c_{r}+\theta\left(a_{m}-a_{r}\right)<0, \frac{\partial \Lambda\left(S_{r}, S_{m}^{*}\left(S_{r}\right), \theta\right)}{\partial S_{r}}<0$ for $\forall S_{r}$, since $\bar{F}_{m}() \geq 0,. \bar{F}_{r}() \leq$.1 , $p_{r} \leq p_{m}$. Therefore, $\Lambda\left(S_{r}, S_{m}^{*}\left(S_{r}\right), \theta\right)$ is a non increasing function of $S_{r}$, hence $S_{r}^{*}=0$.

(ii.) In this case $\frac{\partial \Lambda\left(S_{r}, S_{m}^{*}\left(S_{r}\right), \theta\right)}{\partial S_{r}}$ does not show any monotonous behavior. The given behavior and condition for $S_{r}^{*}$ are direct consequences of concavity of $\Lambda\left(S_{r}, S_{m}^{*}\left(S_{r}\right), \theta\right)$ with respect to $S_{r}$.

\section{Proof of Theorem 2:}

(a.) When the capacity constraint is non-binding Theorem 1 holds. Otherwise, since, $c_{m}<c_{r}$ and $a_{m}<a_{r}, c_{m}-c_{r}+\theta\left(a_{m}-a_{r}\right)<0$ for $\forall \theta>0$. So, due to part (i.) of Lemma 2 , $S_{r}^{*}=0$, for $\forall \theta>0$.

(b.) Since, $c_{m}<c_{r}$ and $a_{m}>a_{r}$,

(i.) $c_{m}-c_{r}+\theta\left(a_{m}-a_{r}\right)<0$ for $\forall \theta<\theta_{0}=\frac{c_{r}-c_{m}}{a_{m}-a_{r}}$. So, due to part (i.) of Lemma 2, $S_{r}^{*}=0, \forall \theta>\theta_{0}$.

(ii.) $c_{m}-c_{r}+\theta\left(a_{m}-a_{r}\right)>0$ for $\forall \theta>\theta_{0}$. Due to part (ii.) of Lemma 2. under $\left(S_{r}^{*}, S_{m}^{*}\right)$ for a given value of $\theta>\theta_{0}, \frac{\partial \Lambda\left(S_{r}^{*}, S_{m}^{*}, \theta\right)}{\partial S_{r}}=0$. Suppose $\theta$ is increased to $\theta^{\prime}$. Under the same $\left(S_{r}^{*}, S_{m}^{*}\right), \frac{\partial \Lambda\left(S_{r}^{*}, S_{m}^{*}, \theta^{\prime}\right)}{\partial S_{r}}>0$. Therefore due to Lemma 2, part (ii.), $S_{r}$ value maximizing $\Lambda\left(S_{r}^{*}, S_{m}^{*}, \theta^{\prime}\right)$ should be greater than or equal to $S_{r}^{*}$.

\section{Proof of Theorem 3:}

(a.) Since, $c_{m}>c_{r}$ and $a_{m}<a_{r}$,

(i.) $c_{m}-c_{r}+\theta\left(a_{m}-a_{r}\right)>0$ for $\forall \theta<\theta_{0}=\frac{c_{r}-c_{m}}{a_{m}-a_{r}}$. Due to part (ii.) of Lemma 2 . under $\left(S_{r}^{*}, S_{m}^{*}\right)$ for a given value of $\theta<\theta_{0}, \frac{\partial \Lambda\left(S_{r}^{*}, S_{m}^{*}, \theta\right)}{\partial S_{r}}=0$. Suppose $\theta$ is increased to $\theta^{\prime}<\theta_{0}$. Under the same $\left(S_{r}^{*}, S_{m}^{*}\right), \frac{\partial \Lambda\left(S_{r}^{*}, S_{m}^{*}, \theta^{\prime}\right)}{\partial S_{r}}<0$. Therefore due to Lemma 2, part (ii.), $S_{r}$ value maximizing $\Lambda\left(S_{r}^{*}, S_{m}^{*}, \theta^{\prime}\right)$ should be less than or equal to $S_{r}^{*}$.

(ii.) $c_{m}-c_{r}+\theta\left(a_{m}-a_{r}\right)<0$ for $\forall \theta>\theta_{0}=\frac{c_{r}-c_{m}}{a_{m}-a_{r}}$. So, due to part (i.) of Lemma 2, $S_{r}^{*}=0, \forall \theta>\theta_{0}$.

(b.) Since, $c_{m}>c_{r}$ and $a_{m}>a_{r}, c_{m}-c_{r}+\theta\left(a_{m}-a_{r}\right)>0$ for $\forall \theta>0$. Due to part (ii.) of Lemma 2. under $\left(S_{r}^{*}, S_{m}^{*}\right)$ for a given value of $\theta>0, \frac{\partial \Lambda\left(S_{r}^{*}, S_{m}^{*}, \theta\right)}{\partial S_{r}}=0$. Suppose $\theta$ is 
increased to $\theta^{\prime}$. Under the same $\left(S_{r}^{*}, S_{m}^{*}\right), \frac{\partial \Lambda\left(S_{r}^{*}, S_{m}^{*}, \theta^{\prime}\right)}{\partial S_{r}}>0$. Therefore due to Lemma 2, part (ii.), $S_{r}$ value maximizing $\Lambda\left(S_{r}^{*}, S_{m}^{*}, \theta^{\prime}\right)$ should be greater than or equal to $S_{r}^{*}$.

\section{Appendix III-Proofs of Properties on the Effect of Substitution Policy on the Optimal Order-up-to Levels}

Let $\left(S_{r}^{*}, S_{m}^{*}\right)$ be the optimal order-up-to levels of PR and PM, respectively, under substitution policy.

Proof of Property 1: In this case under $S_{m}^{*}$, equation (2) is equal to zero. Equating (2) to zero and re-writing it yields:

$$
\bar{F}_{m}\left(S_{m}^{*}\right)=-\frac{p_{r}}{p_{m}} \int_{0}^{S_{m}^{*}} \bar{F}_{r}\left(S_{r}^{*}+S_{m}^{*}-x_{m}\right) f_{m}\left(x_{m}\right) d x_{m}+\frac{c_{m}}{p_{m}}
$$

Since $\frac{p_{r}}{p_{m}} \int_{0}^{S_{m}^{*}} \bar{F}_{r}\left(S_{r}^{*}+S_{m}^{*}-x_{m}\right) f_{m}\left(x_{m}\right) d x_{m} \geq 0$, due to optimality condition given in (9) for the case where substitution policy not applied

$$
\bar{F}_{m}\left(S_{m}^{*}\right) \leq \frac{c_{m}}{p_{m}}=\bar{F}_{m}\left(S_{m}^{N S}\right) .
$$

Therefore, $S_{m}^{*} \geq S_{m}^{N S}$ since $\overline{F_{m}}($.$) is a non increasing function.$

Proof of Property 2: In this case under $S_{r}^{*}$, equation (3) is equal to zero. Equating (3) to zero and re-writing it yields:

$$
\int_{0}^{S_{m}} \bar{F}_{r}\left(S_{r}^{*}+S_{m}-x_{m}\right) f_{m}\left(x_{m}\right) d x_{m}+\bar{F}_{r}\left(S_{r}^{*}\right) \bar{F}_{m}\left(S_{m}\right)=\frac{c_{r}}{p_{r}} .
$$

Note that $\bar{F}_{r}\left(S_{r}^{*}+S_{m}-x_{m}\right) \leq \bar{F}_{r}\left(S_{r}^{*}\right)$ for $\forall x_{m} \in\left[0, S_{m}\right]$ since $\bar{F}_{r}($.$) is a non increasing$ function. Therefore from (19) and (8),

$$
\begin{gathered}
\bar{F}_{r}\left(S_{r}^{*}\right) \bar{F}_{m}\left(S_{m}\right)+\int_{0}^{S_{m}} \bar{F}_{r}\left(S_{r}^{*}\right) f_{m}\left(x_{m}\right) d x_{m} \geq \frac{c_{r}}{p_{r}}=\bar{F}_{r}\left(S_{r}^{N S}\right) \\
\bar{F}_{r}\left(S_{r}^{*}\right) \bar{F}_{m}\left(S_{m}\right)+\bar{F}_{r}\left(S_{r}^{*}\right)\left(1-\bar{F}_{m}\left(S_{m}\right)\right) \geq \bar{F}_{r}\left(S_{r}^{N S}\right) \\
\bar{F}_{r}\left(S_{r}^{*}\right) \geq \bar{F}_{r}\left(S_{r}^{N S}\right)
\end{gathered}
$$


Therefore, $S_{r}^{*} \leq S_{r}^{N S}$ since $\bar{F}_{r}($.$) is a non increasing function.$

Proof of Property 3: can be shown as in Property 1 using optimality conditions (5) and (11) instead of (2) and (9).

Proof of Property 4: can be shown as in Property 2 using optimality conditions (6) and (10) instead of (3) and (8).

\section{References}

1. Ferrer G. The Economics of Personal Computer Remanufacturing. Resour Conserv Recycling 1997;21:79-108.

2. Ferrer G. The Economics of Tire Remanufacturing. Resour Conserv Recycling 1997;19:221255.

3. Ayres R, Ferrer G and van Leynseele T. Eco-Efficiency, Asset Recovery and Remanufacturing. Eur Mgmt J 1997;15(5):557-574.

4. Maslennikova I and Foley D. Xerox Approach to Sustainability. Interfaces 2000;30:226233.

5. Richter K. The EOQ Repair and Waste Disposal Model with Variable Setup Numbers. Eur J Opl Res 1996;96:313-324.

6. Richter K and Dobos I.Analysis of the EOQ Repair and Disposal Problem with Integer Setup Numbers. Int J Prod Econ 1999;59:463-467.

7. Richter K and Sombrutzki M. Remanufacturing Planning for the Reverse Wagner/Whitin Models. Eur J Opl Res 2000;121:304-315.

8. Teunter RH. Economic Ordering Quantities for Recoverable Item Inventory Systems. Naval Res Logistics 2001;48:484-495.

9. van der Laan EA, Dekker R, Salomon M and Ridder A. An $(s, Q)$ Inventory Model with Remanufacturing and Disposal. Int J Prod Econ 1996;46-47:339-350.

10. van der Laan EA, Dekker R and Salomon M. Product Remanufacturing and Disposal: A numerical Comparison of Alternative Control Strategies. Int J Prod Econ 1996;45:489498.

11. van der Laan EA and Salomon M. Production Planning and Inventory Control with Remanufacturing and Disposal. Eur J Opl Res 1997;102:264-278.

12. van der Laan EA, Salomon M, Dekker R, and Van Wassenhove L N. Inventory Control in Hybrid Systems with Remanufacturing. Mgmt Sci 1999;45(5):733-747. 
13. van der Laan EA, Salomon M and Dekker R. An Investigation of Lead-Time Effects in Manufacturing/Remanufacturing Systems Under Simple PUSH and PULL Control Strategies. Eur J Opl Res 1999:115;195-214.

14. Toktay LB, Wein LM and Zenios SA. Inventory Management of Remanufacturable Products. Mgmt Sci 2000;46(11):1412-1426.

15. Bayındır ZP, Erkip N, and Güllü R. A Model to Evaluate Inventory Costs in a Remanufacturing Environment. Int J Prod Econ 2003;81-82:597-607.

16. Inderfurth K, de Kok AG and Flapper SDP. Product Recovery in Stochastic Remanufacturing Systems with Multiple Reuse Options. Eur J Opl Res 2001;133(1):130-152.

17. Kiesmüller G, and van der Laan EA. An Inventory Model with Dependent Product Demands and Returns. Int J Prod Econ 2001;72:73-87.

18. Inderfurth K, and van der Laan EA. Leadtime Effects and Policy Improvement for Stochastic Inventory Control with Remanufacturing. Int J Prod Econ 2001;71:381-390.

19. Debo LG, Toktay LB, and van Wassenhove LN. Market Segmentation and Production Technology Selection for Remanufacturable Products. Working Paper, 2001, INSEAD.

20. Parlar M. Game Theoretic Analysis of the Substitutable Product Inventory Problem with Random Demands. Naval Res Logistics 1988;38:397-409.

21. Parlar M. Optimal Ordering Policies for a Perishable and Substitutable Product. INFOR 1985;23(2):182-195.

22. Pasternack BA and Drezner Z. Optimal Inventory Policies for Substitutable Commodities with Stochastic Demand. Naval Res Logistics 1991;38:221-240.

23. Wang Q and Parlar M. A Three-Person Game Theory Model Arising in Stochastic Inventory Control Theory. Eur J Opl Res 1994;76:83-97.

24. Bassok Y, Anupindi R and Akella R. Single-period Multiproduct Inventory Models with Substitution. Opns Res 1999;47(4):632-642.

25. Smith SA and Agrawal N. Management of Multi-Item Retail Inventory Systems with Demand Substitution. Opns Res 2000;48(1):50-60.

26. Ignall E and Veinott AFJR. Optimality of Myopic Inventory Policies for Several Substitute Products. Mgmt Sci 1969;15(5):284-304.

27. McGillivray AR and Silver ED. Some Concepts for Inventory Control under Substitutable Demand. INFOR 1978;16(1):47-63. 
28. Avşar ZM and Baykal-Gürsoy M. Inventory Control under Substitutable Demand: A Stochastic Game Application. Naval Res Logistics 2002;49(4):359-375.

29. Bayındır ZP, Erkip N, Güllü R. Assessing the Benefits of Remanufacturing under OneWay Substitution. Technical report 2002;02-02,Department of Industrial Engineering, Middle East Technical University.

Table 1: The Behavior of $S_{r}^{*}$ with respect to an increase in $\theta,\left(\theta_{0}=\frac{c_{r}-c_{m}}{a_{m}-a_{r}}\right)$

\begin{tabular}{|c|c|c|}
\hline & $c_{r}<c_{m}$ & $c_{r}>c_{m}$ \\
\hline$a_{r}<a_{m}$ & non decreasing & $-S_{r}^{*}=0$ up-to $\theta_{0}$, \\
& & -non decreasing \\
\hline$a_{r}>a_{m}$ & -non increasing & $S_{r}^{*}=0$ \\
\hline
\end{tabular}

Table 2: Available Capacity Levels under which the Utilization Ratio of Remanufacturing Option Drops to Zero under Substitution $\left(a_{r}=2\right)$

\begin{tabular}{|c|c|c|c|}
\hline Scenario & Case A & Case B & Case C \\
\hline S1 & 39 & 45 & $\infty$ \\
\hline S2 & 8 & 8 & $\infty$ \\
\hline S3 & 20 & $\infty$ & $\infty$ \\
\hline S4 & 4.21 & 5.51 & $\infty$ \\
\hline S5 & 2.67 & 3.62 & $\infty$ \\
\hline S6 & 3.49 & 4.52 & $\infty$ \\
\hline
\end{tabular}


Table 3: Available Capacity Levels under which the Utilization Ratio of Remanufacturing Option Drops to Zero under No-Substitution $\left(a_{r}=2\right)$

\begin{tabular}{|c|c|c|c|}
\hline Scenario & Case A & Case B & Case C \\
\hline S1 & 16 & 19 & 24 \\
\hline S2 & 2 & 2 & 3 \\
\hline S3 & 17 & 21 & 27 \\
\hline S4 & 0.75 & 0.90 & 1.38 \\
\hline S5 & 0.64 & 0.80 & 1.31 \\
\hline S6 & 1.42 & 1.76 & 2.55 \\
\hline
\end{tabular}

Table 4: Available Capacity Levels under which the Utilization Ratio of Remanufacturing Option Reaches 1 under Substitution $\left(a_{r}=0.5\right)$

\begin{tabular}{|c|c|c|c|}
\hline Scenario & Case A & Case B & Case C \\
\hline S1 & 28 & 18 & 2 \\
\hline S2 & 31 & 20 & 4 \\
\hline S3 & 3 & 1 & 4 \\
\hline S4 & 2.91 & 1.62 & 0.21 \\
\hline S5 & 2.91 & 1.62 & 0.21 \\
\hline S6 & 1.45 & 0.81 & 0.1 \\
\hline
\end{tabular}


Table 5: Available Capacity Levels under which the Utilization Ratio of Remanufacturing Option Reaches 1 under No-Substitution $\left(a_{r}=0.5\right)$

\begin{tabular}{|c|c|c|c|}
\hline Scenario & Case A & Case B & Case C \\
\hline S1 & 28 & 18 & 3 \\
\hline S2 & 31 & 20 & 4 \\
\hline S3 & 3 & 2 & 2 \\
\hline S4 & 1.45 & 0.81 & 0.11 \\
\hline S5 & 2.98 & 1.62 & 0.21 \\
\hline S6 & 1.42 & 0.81 & 0.10 \\
\hline
\end{tabular}

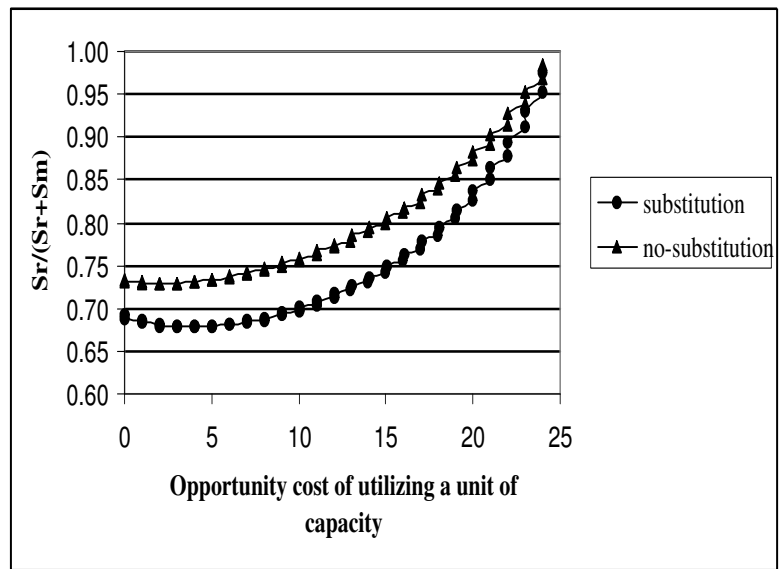

Figure 1: Capacity allocated to remanufacturing under the optimal solution under substitution and no-substitution, Case A, S4, $a_{r}=0.5$ 


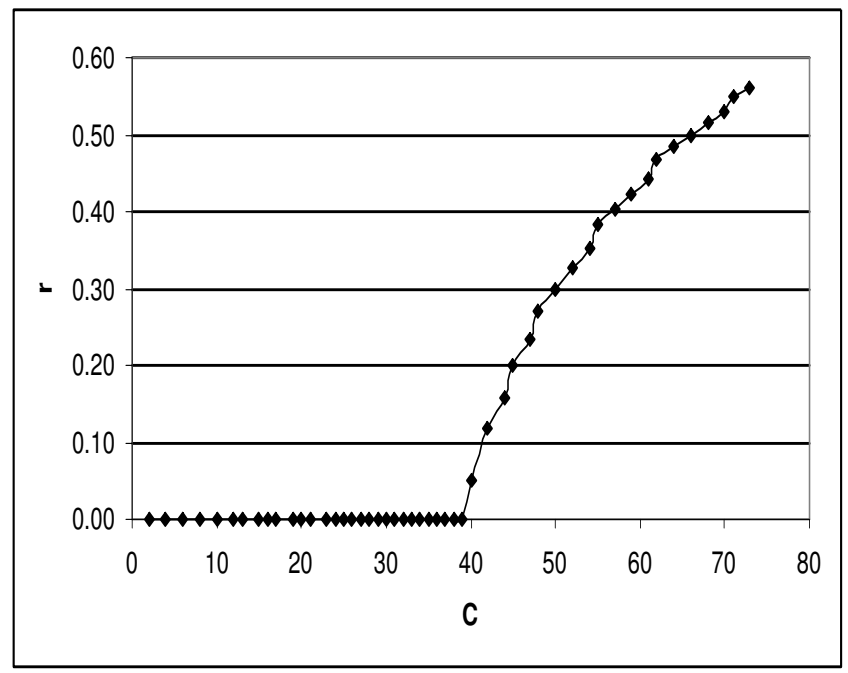

(a) CASE A

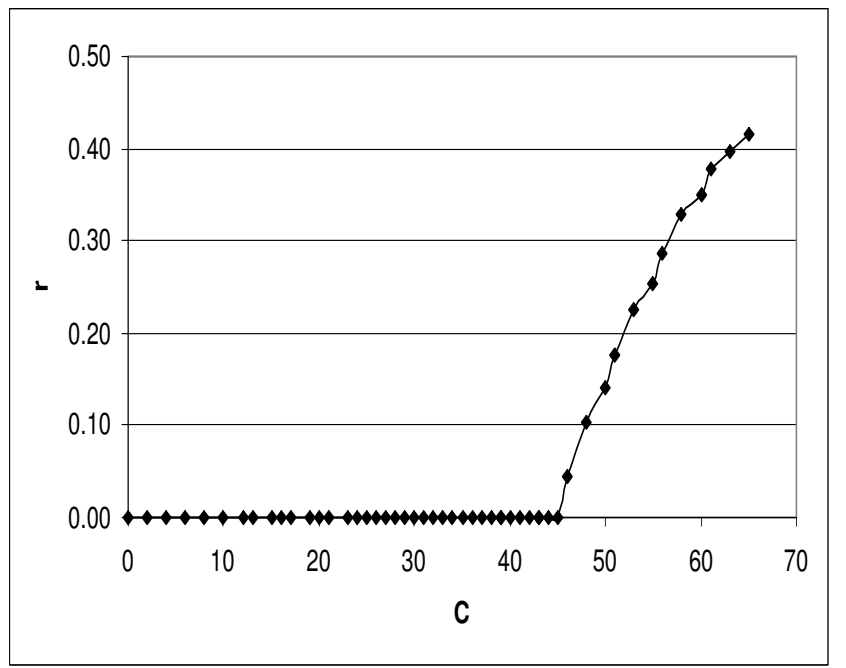

(b) CASE B

Figure 2: Optimal Utilization Ratio of Remanufacturing, $r=S_{r} /\left(S_{r}+S_{m}\right)$, at Different Available Capacity Levels under Substitution, S1, $a_{r}=2$. 


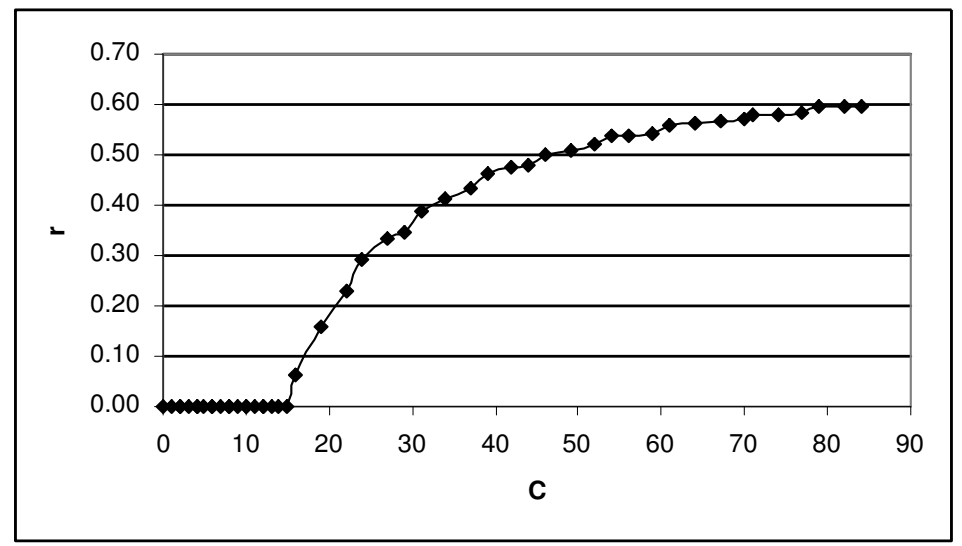

(a) CASE A

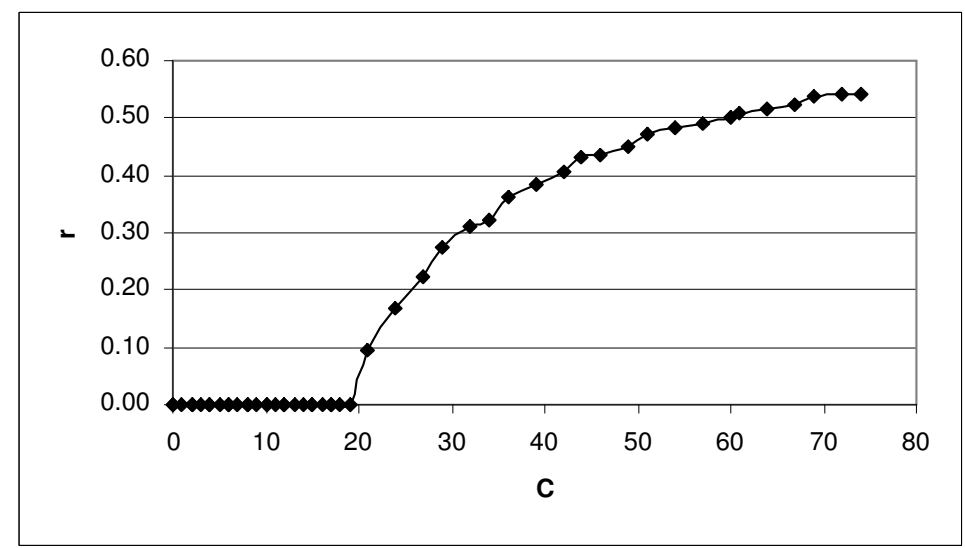

(b) CASE B

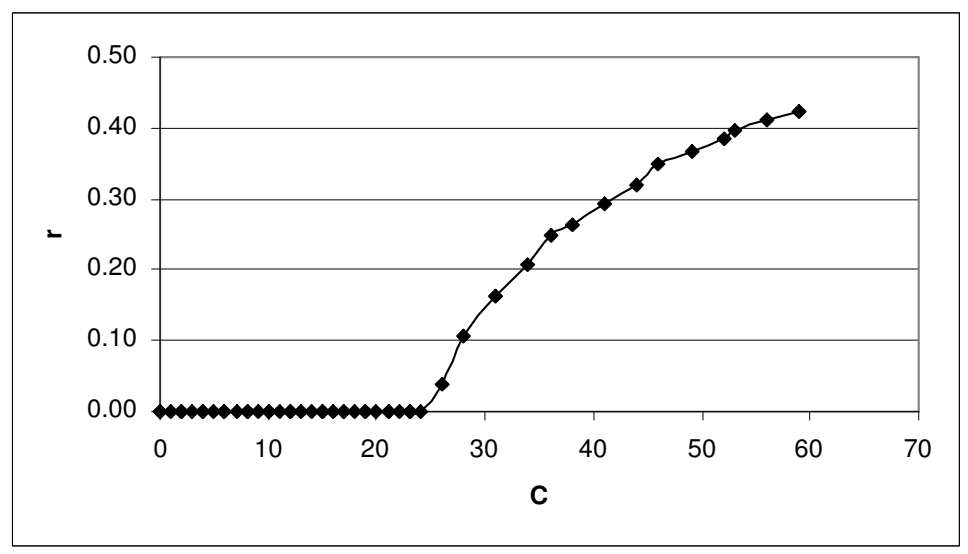

(c) CASE C

Figure 3: Optimal Utilization Ratio of Remanufacturing, $r=S_{r} /\left(S_{r}+S_{m}\right)$, at Different Available Capacity Levels under No-Substitution, S1, $a_{r}=2$. 


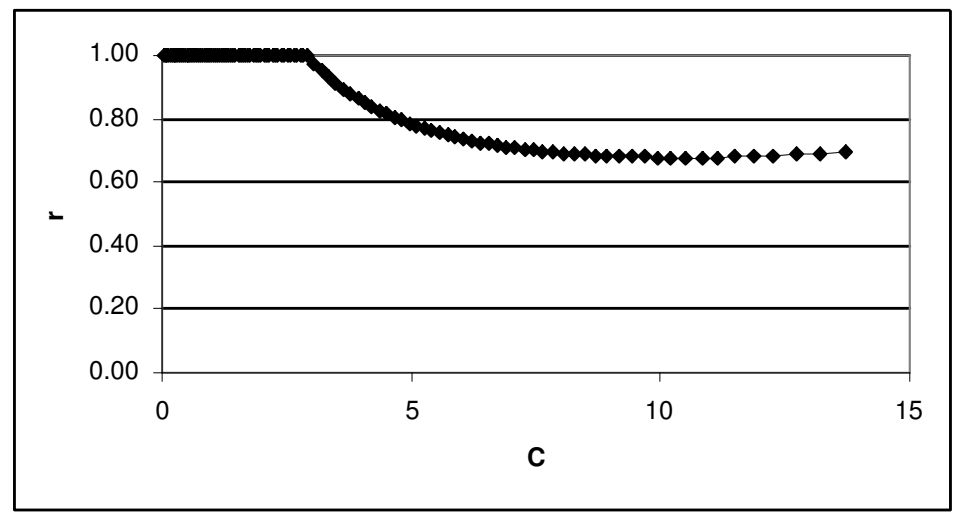

(a) CASE A

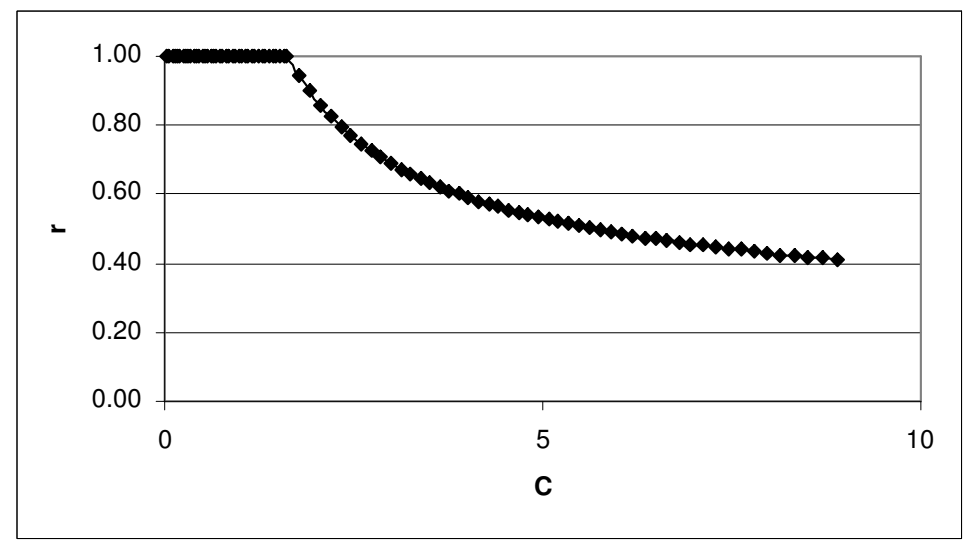

(b) CASE B

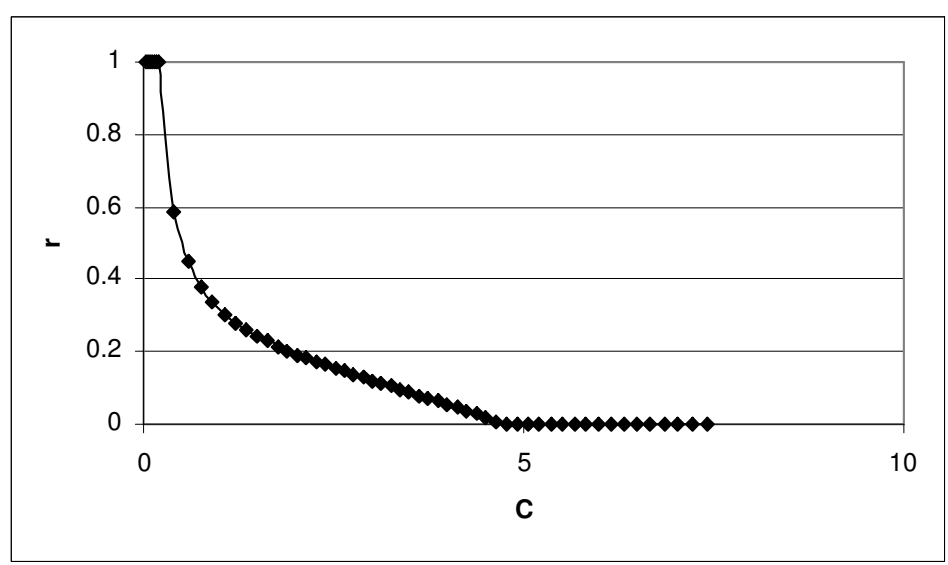

(c) CASE C

Figure 4: Optimal Utilization Ratio of Remanufacturing, $r=S_{r} /\left(S_{r}+S_{m}\right)$, at Different Available Capacity Levels under Substitution, S4, $a_{r}=0.5$. 


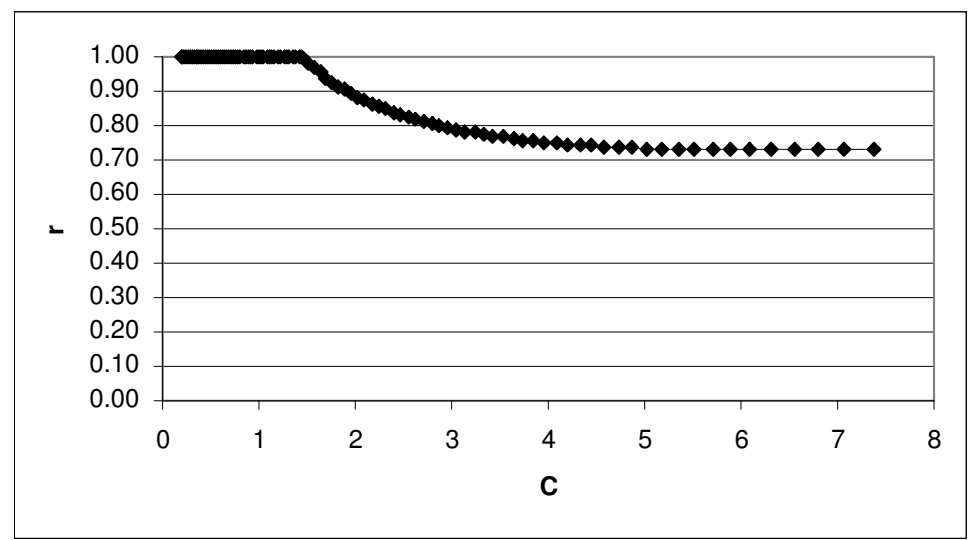

(a) CASE A

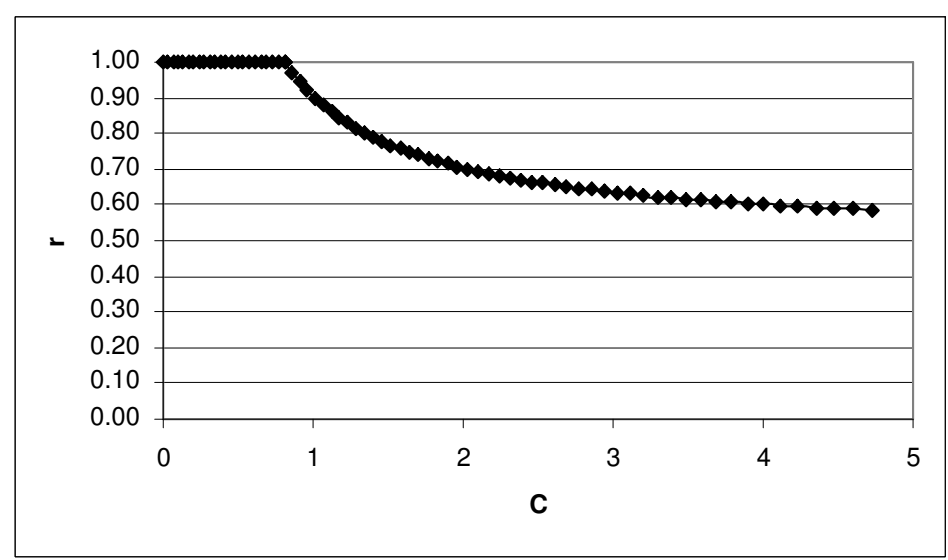

(b) CASE B

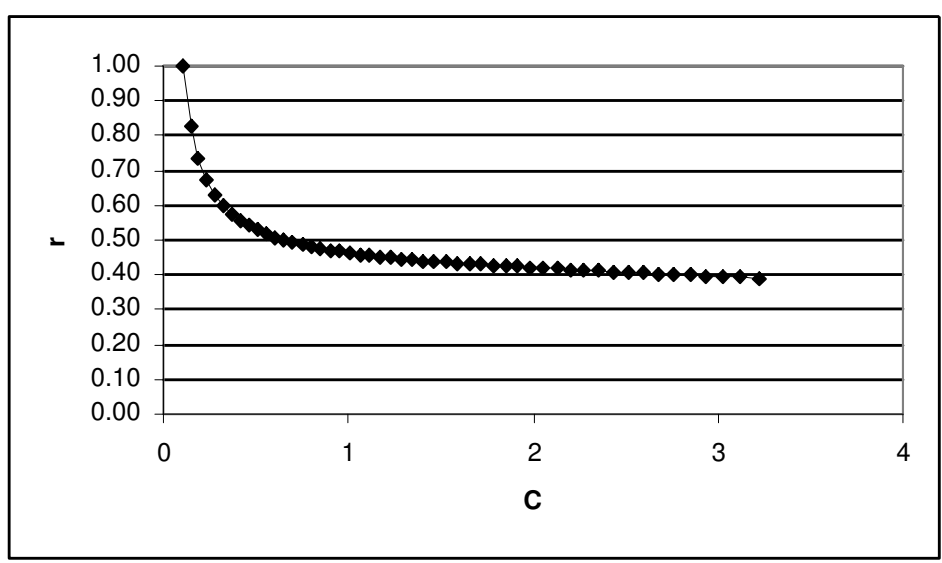

(c) CASE C

Figure 5: Optimal Utilization Ratio of Remanufacturing, $r=S_{r} /\left(S_{r}+S_{m}\right)$, at Different Available Capacity Levels under No-Substitution, S4, $a_{r}=0.5$. 


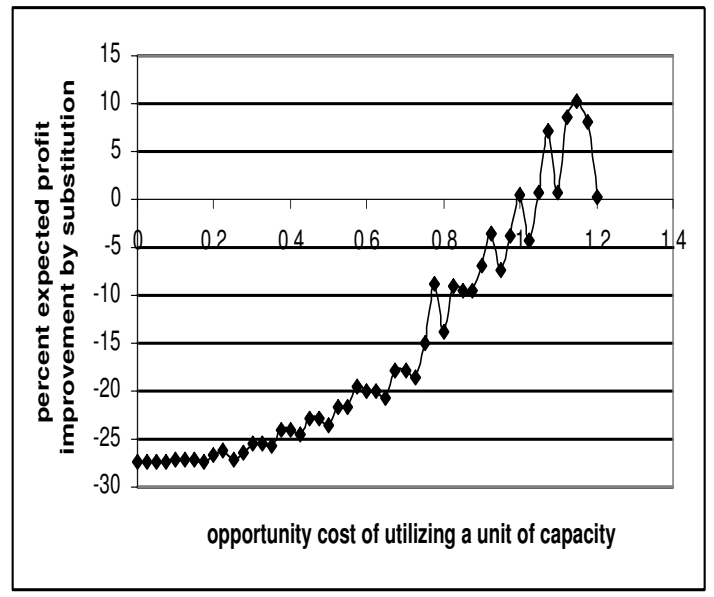

(a) $a_{r}=0.5$

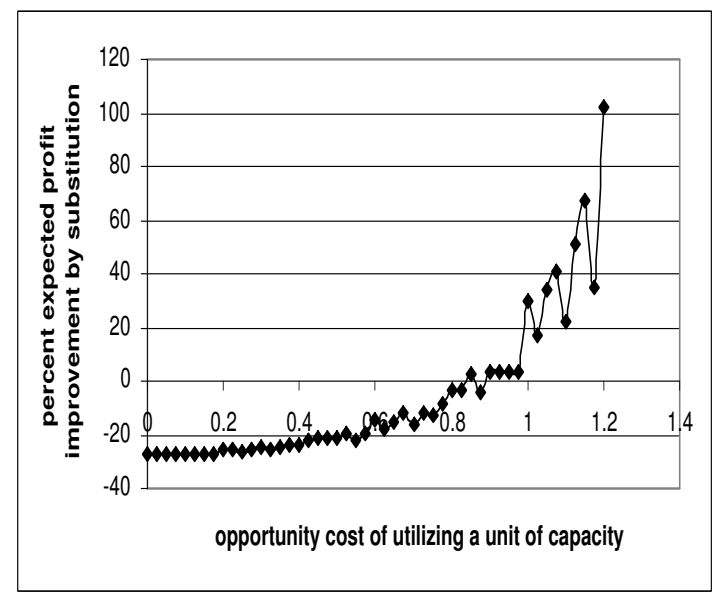

(b) $a_{r}=1$

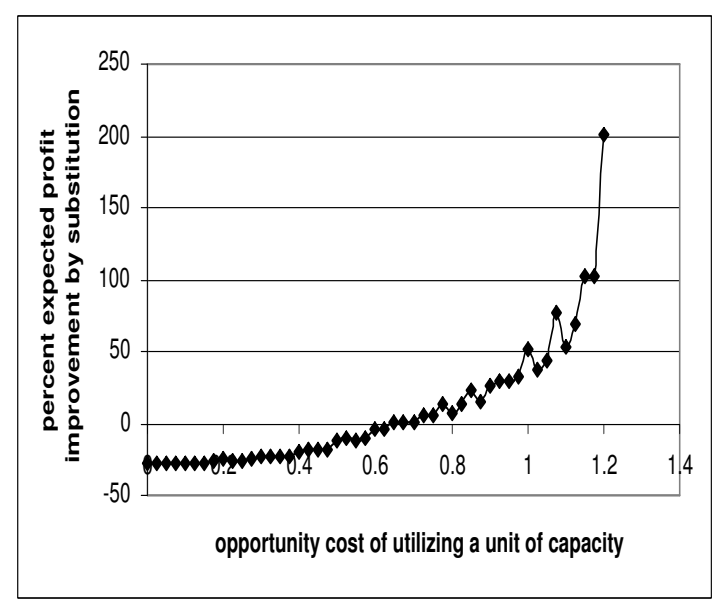

(c) $a_{r}=2$

Figure 6: Percent Expected Profit Improvement by Substitution, S3, Case A. 